\title{
HLA and multiple sclerosis in south east Wales
}

\author{
R J SWINGLER,* P F KIRK, * C DARKE,† D A S COMPSTON* \\ From the Department of Neurology,* University of Wales College of Medicine, and the Tissue Typing \\ Laboratory, $\dagger$ Blood Transfusion Centre, Cardiff, UK
}

SUMMARY A stronger association has been found between multiple sclerosis and HLA-DR2 than -DQw1 in south east Wales (prevalence c $113 / 10^{5}$ ) in contrast to recent observations in north east Scotland (prevalence $178 / 10^{5}$ ). The complex relationship between the HLA system and multiple sclerosis, demonstrated in this and other studies, is explained more easily under a polygenic model of inheritance, in which environmental events and genes interact, than by the presence of a single susceptibility gene.

The evidence indicating that susceptibility to multiple sclerosis is determined by genes encoded within the HLA system is open to different interpretations; before constructing hypotheses which take the various observations into account, it is necessary first to identify the closest markers of susceptibility to the disease. Progressively stronger associations are observed between multiple sclerosis and the linked alleles HLA-A3, -B7, -Dw2, and -DR2 in patients of north European origin and a relationship has recently been described between multiple sclerosis and HLADQw1 in north east Scotland, ${ }^{1}$ where there is no association with HLA-DR2 although the prevalence of multiple sclerosis is very high. ${ }^{2}$ The question arises whether HLA-DQwl is a closer marker of susceptibility to multiple sclerosis than the linked allele HLA-DR2 and of more biological significance for the pathogenesis. We have therefore investigated associations between these two antigens in south east Wales where direct correlation with a recent prevalence study can also be made.

\section{Patients and methods}

Fifty seven unrelated caucasoid patients with clinically definite multiple sclerosis were selected at random from a population-based register and typed for class 1 and 2 antigens in the 7 th Workshop extended lymphocytotoxicity test ${ }^{3}$ using locally evaluated antisera standardised against workshop reagents. Antigen frequencies were compared with

Address for reprint requests: D A S Compston, University of Wales College of Medicine, Heath Park, Cardiff CF44XN, UK.

Received 24 October 1986 and in revised form 23 December 1986. Accepted 5 January 1987 results in 600 (HLA-A and -B) and 407 (HLA-DR and -DQ) randomly selected local caucasoid controls. All antigen assignments were made without prior knowledge of the disease status. The significance of associations between multiple sclerosis and particular phenotypes was examined using the chi-square test and relative risks (RR) with $95 \%$ confidence limits were calculated. Lastly, correlation coefficients between specific antigen frequencies and prevalence were computed.

\section{Results}

There was an increased frequency of HLA-A3 $(26 \cdot 3 \%$ vs $24 \cdot 3 \%$ :ns), -B7 (40.4\% vs $28 \cdot 2 \%$ :ns) and -DR2 $(50.7 \%$ vs $26.5 \%$ :p $<0.001)$ in patients compared with controls (table 1). A similar trend was observed comparing the frequencies of HLA-DQw1 in patients $(\mathrm{n}=45,71 \cdot 1 \%)$ and controls $(59 \%)$ but this was not statistically significant. The relative risk for developing multiple sclerosis in the presence of HLA-DR2 or -DQw1 was 2.87 (95\% confidence interval 1.66-4.98) and $1.7(95 \%$ confidence interval $0.88-2 \cdot 21)$ respectively. Previously published antigen frequencies and statistics for north east Scotland ${ }^{1}$ are also shown in table 1 . Table 2 shows the relative risk for developing multiple sclerosis in south east Wales in the presence of different combinations of class two antigens. Table 3 shows the relationship between the frequency of HLA-DR2 and -DQw1 in patients and controls together with prevalence of multiple sclerosis in areas where all three variables have been studied. Although the prevalence of multiple sclerosis correlates directly with normal variations in the frequency of HLA-DR2 $(r=0.952)$ and $-D Q w 1(r=0.955)$ there are too few observations to achieve statistical significance. 
Table 1 The frequency of class 1 and 2 antigens in patients with multiple sclerosis and controls from south east Wales and north east Scotland

\begin{tabular}{|c|c|c|c|c|}
\hline & \multicolumn{2}{|l|}{ SE Wales } & \multicolumn{2}{|l|}{ NE Scotland } \\
\hline & Multiple sclerosis & Controls & Multiple sclerosis & Controls \\
\hline $\begin{array}{l}\text { A3 } \\
\text { B7 } \\
\text { DR2 } \\
\text { DQw1 }\end{array}$ & $\begin{array}{l}15 / 57(26 \cdot 3 \%) \\
23 / 57(40 \cdot 4 \%) \\
29 / 57(50 \cdot 7 \%) \\
32 / 45(71 \cdot 1 \%)\end{array}$ & $\begin{array}{l}146 / 600(24 \cdot 3 \%) \\
169 / 600(28 \cdot 2 \%) \\
108 / 407(26 \cdot 5 \%) \\
240 / 407(59.0 \%)\end{array}$ & $\begin{array}{l}- \\
- \\
87 / 178(49 \%) \\
137 / 178(77 \%)\end{array}$ & $\begin{array}{l}- \\
\overline{52} / 128(41 \%) \\
79 / 128(62 \%)\end{array}$ \\
\hline
\end{tabular}

DR2 in SE Wales patients vs controls: $\left(\chi^{2}=15.1 ; \mathrm{p}<0.0005\right)$. Relative risk 2.87 (95\% CI 1.66-4.98). DR2 in NE Scotland patients vs controls: $\left(\chi^{2}=2 \cdot 04 ;\right.$ NS). Relative risk $1.43(95 \%$ CI $0.88-2 \cdot 21)$. DQwl in SE Wales patients vs controls: $\left(\chi^{2}=2 \cdot 49 ;\right.$ NS). Relative risk 1.7 $(95 \%$ CI $0.87-3 \cdot 35)$. DQw1 in Scottish patients vs controls: $\left(\chi^{2}=8.34 ; p<0.005\right)$. Relative risk 2.07; (95\% CI 1.79-4.07). DR2 in SE Wales patients vs NE Scotland patients: $\left(\chi^{2}=0.04 ;\right.$ NS). DR2 in SE Wales controls vs NE Scotland controls: $\left(\chi^{2}=10 \cdot 2 ; \mathrm{p}<0.005\right)$. DQw1 in SE Wales patients vs NE Scotland patients: $\left(\chi^{2}=0.67\right.$; NS). DQw1 in SE Wales controls vs NE Scotland controls: $\left(\chi^{2}=0 \cdot 31\right.$; NS).

Table 2 The relative risk for developing multiple sclerosis in patients possessing different combinations of class 2 antigens in south east Wales

\begin{tabular}{|c|c|c|c|c|c|c|}
\hline & & $\begin{array}{l}\text { Mulitple } \\
\text { sclerosis }\end{array}$ & Controls & $\chi^{2}$ & $R R$ & $p$ \\
\hline DQw1 - & DR2 - & $13 / 45$ & $167 / 407$ & $2 \cdot 5$ & 0.58 & NS \\
\hline DQwl + & $\begin{array}{l}\text { DR2 + } \\
\text { DR2 - } \\
\text { DR2 + }\end{array}$ & $\begin{array}{r}0 / 45 \\
11 / 45 \\
21 / 45\end{array}$ & $\begin{array}{r}0 / 407 \\
132 / 407 \\
108 / 407\end{array}$ & $\begin{array}{l}\overline{1 \cdot 2} \\
8 \cdot 05\end{array}$ & $\begin{array}{l}\overline{0.67} \\
2 \cdot 19\end{array}$ & $\begin{array}{l}\overline{N S} \\
<0.005\end{array}$ \\
\hline
\end{tabular}

Table 3 The frequency of class 2 antigens in cases and controls and the prevalence of multiple sclerosis in south east Wales, ${ }^{10}$ north east Scotland ${ }^{2}$ and Kuwait. ${ }^{5}$

\begin{tabular}{|c|c|c|c|c|}
\hline & Aberdeen & Cardiff & Mediterranean Arabs & Gulf Arabs \\
\hline \multicolumn{5}{|l|}{ HLA-DR2 } \\
\hline MS & $49 \cdot 0 \%$ & $50 \cdot 7 \%$ & $65 \cdot 2 \%$ & $54 \cdot 1 \%$ \\
\hline Controls & $41.0 \%$ & $26 \cdot 5 \%$ & $18 \cdot 8 \%$ & $38 \cdot 2 \%$ \\
\hline $\mathrm{RR}$ & 1.43 & 2.87 & $8 \cdot 1$ & 1.96 \\
\hline$P$ value & NS & $<0.001$ & $<0.001$ & 0.25 \\
\hline \multicolumn{5}{|l|}{ HLA-DQw1 } \\
\hline MS & $77 \cdot 0 \%$ & $71 \cdot 1 \%$ & $60 \cdot 8 \%$ & $45 \cdot 8 \%$ \\
\hline Controls & $62.0 \%$ & $59.0 \%$ & $30 \cdot 2 \%$ & $42.5 \%$ \\
\hline RR & 2.07 & 1.7 & $3 \cdot 4$ & $1 \cdot 1$ \\
\hline P value & $<0.005$ & NS & $<0.05$ & NS \\
\hline \multicolumn{5}{|l|}{$\begin{array}{l}\text { NS } \\
\text { Prev } / 10^{5}\end{array}$} \\
\hline $\operatorname{Prev} / 10^{\circ}$ & 178 & $\mathrm{cll} 3$ & $7 \cdot 8$ & $4 \cdot 4$ \\
\hline
\end{tabular}

MS = multiple sclerosis.

\section{Discussion}

One interpretation of the relationship between HLA and multiple sclerosis is that the disease is determined by a single gene, maintained in linkage disequilibrium with HLA-DR2 and -DQw1, in northern Europe, and with other haplotypes in some different populations. ${ }^{4}$ If a single multiple sclerosis susceptibility gene exists it is important to determine its closest identifiable marker. We have previously suggested that the distribution of multiple sclerosis in the United Kingdom is influenced by regional variations in the normal frequency of HLA-DR2; there is a similar relationship between the prevalence of multiple sclerosis and normal frequency of HLA-DQwl, as would be expected if the loci encoding these antigens are in linkage disequilibrium with a multiple sclerosis susceptibility gene. Based on the findings in north east Scotland, it has been suggested that this hypothetical gene lies closer to the HLA-DQ than -DR locus. ${ }^{1}$ Our finding of a stronger association between multiple sclerosis and HLA-DR2 is south east Wales points to the 
opposite conclusion and is in agreement with the findings in Mediterranean Arabs. ${ }^{5}$ Taken together, the evidence suggests that if a single susceptibility gene exists it is no closer to the HLA-DQ than -DR locus.

An alternative explanation for the findings is that, through their effect on immune responsiveness, multiple sclerosis associated alleles themselves confer susceptibility to exogenous events responsible for initiating the disease process, different individuals being selected as susceptible depending on local environmental conditions. This hypothesis embodies the concept of gene complementation but can be extended to include interaction with genes encoded on other chromosomes.

Evidence favouring polygenic inheritance is provided by pedigree analysis and HLA linkage studies. In the Orkneys, estimates of heritability, consanguinity and kinship coefficients do not favour the recent introduction of a major gene ${ }^{6}$ Elsewhere, it is necessary to postulate genetic heterogeneity or markedly reduced penetrance in order to explain the segregation pattern of HLA haplotypes in multiplex families. ${ }^{7}$ Unlinked genes, including HLA alleles and immunoglobulin heavy chain allotypes encoded on the 14th chromosome, have already been shown to confer susceptibility within a single population ${ }^{8}$ and markedly different associations exist in different parts of the world. ${ }^{9}$

At present it is not known how gene products and environmental events interact in conferring susceptibility to multiple sclerosis. The influence of each factor will depend on the absolute risk conferred and its frequency in the at-risk population. Incidence of the disease increases as any risk factor becomes more frequent in the normal population, the magnitude of this effect varying with the absolute risk conferred. Disease associations are based on differences in frequency of any risk factor between cases and controls, but these do not necessarily reflect biological significance. They become obscured in any region where the frequency in controls approximates to that in cases. In a population where a major risk factor is common and a minor one rare, prevalence of the disease will be high, but associations with the major risk factor may disappear and the distribution of multiple sclerosis within this population will then be determined more by the presence in individuals of less common complementary genes or exogenous factors. It is possible that the class 2 HLA associations in the Orkneys and Aberdeen may be more important than their weak associations suggest, for although the relative risks are small, these genes are present in a high proportion of the population and may be making a large contribution to the incidence of disease. ${ }^{10}$

In areas where all susceptibility gene frequencies are low in the normal population, the chance that an individual will possess each risk factor and be exposed to environmental conditions necessary for the development of multiple sclerosis will be also low, so that incidence of the disease will fall. Under these circumstances the gene which confers the greatest absolute risk will show the strongest association and more detailed studies involving large numbers will always be required to demonstrate the weaker associations.

The implications of this multifactorial hypothesis, in which individual risk factors confer differing susceptibility and are not evenly distributed, is that in some studies environmental conditions and in others genetic factors will appear to be of exclusive importance, giving the impression of greater aetiological heterogeneity than may in fact be the case. Unless multiple sclerosis as presently defined is the expression of many different diseases, only the polygenic model can account for the observations of multiple genetic associations within and between populations.

\section{References}

1 Francis DA, Batchelor JR, McDonald WI, Hern JEC, Downie AW. Multiple sclerosis and HLA DQw1. Lancet 1986;i:211.

2 Downie AW, Phadke JG. The Chief Scientist reports: multiple sclerosis in north east Scotland. Health Bulletin (Edin) 1984;42:151-6.

3 Bodmer JG, Pickbourne P, Richards S. Ia serology. In: Bodmer WF, Batchelor JR, Bodmer JG, Festenstein H, Morris PJ, eds. Histocompatibility Testing 1977. Copenhagen: Munksgaard, 1978:35-84.

4 Terasaki PI, Mickey MR. A single mutation hypothesis for multiple sclerosis based on the HLA system. Neurology 1976;26:56-8.

5 Al-Din ASN, al-Saffar M, Siboo R, Behbehani K. Association between HLA-D region epitopes and multiple sclerosis in Arabs. Tissue Antigens 1986;27:196-200.

6 Roberts DF, Roberts MJ, Poskanser DC. Genetic analysis of multiple sclerosis in Orkney. J Epidemiol Community Health 1979;33:229-35.

7 Ho H-Z, Tiwari JL, Haile RW, Terasaki PI, Morton NE. HLA linked and unlinked determinants of multiple sclerosis. Immunogenetics 1982;15:509-17.

8 Stewart GJ, Kirk RL. The genetics of multiple sclerosis. In: Hallpike J, Adams C, Tourtellote W, eds. Multiple Sclerosis. London: Chapman and Hall, 1982:97-128.

9 Tiwari JL, Terasaki PI. HLA and Disease Associations. New York: Springer-Verlag 1985;152-67.

10 Swingler RJ, Compston DAS. The distribution of multiple sclerosis in the United Kingdom. J Neurol Neurosurg Psychiatry 1986;49:1115-24. 